trend patterns, seasonality changes, and transitions on a regional scale.

Currently, nine different model simulations are available (and will be made publically available through the PANGAEA database at http://www.pangaea.de/). A preliminary analysis shows common patterns of temperature changes (Fig. 2). More analysis is necessary to clarify the model differences in response to orbital forcing. Using statistical analysis of the model results, variability modes and their amplitude during the Holocene are identified in the model experiments. Our analyses reveal heterogeneity in temperature and precipitation trends and yield a quantification of robust features in the models. The variations in the large-scale atmosphere-ocean circulation and feedback mechanisms between the components of the climate system will be investigated in the future. Further analysis will also include the development of Southern Hemisphere wind and vegetation changes. We invite the paleoclimate community to participate in this initiative. Those that are interested are invited to email the author to obtain the required transient simulations and data information.

\section{References}

Schulz, M. and Paul, A., 2009: Integrated analysis of interglacial climate dynamics - INTERDYNAMIC Status Seminar, PAGES news, 17 $84-85$.

\title{
Advances in varved sediment studies during the last 10 years
}

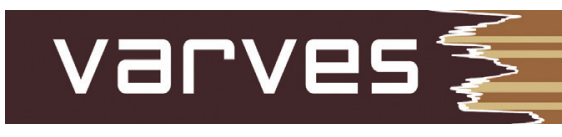

\section{$1^{\text {st }}$ PAGES Varves Working Group workshop, Palmse, Estonia, 7-9 April 2010}

\author{
Pierre Francus ${ }^{1}$, A.E.K. Ojala ${ }^{2}$, A. Heinsalu ${ }^{3}$, R. Behl4, M. Grosjean ${ }^{5}$ and B. Zolitschka ${ }^{6}$ \\ 'National Institute of Scientific Research, Québec, Canada; pfrancus@ete.inrs.ca \\ ${ }^{2}$ Geological Survey of Finland, Espoo; Institute of Geology, Tallinn University of Technology, Estonia; ${ }^{4}$ California State University, Long Beach, \\ USA; ${ }^{5}$ University of Bern, Switzerland; ${ }^{6}$ University of Bremen, Germany
}

A varve is a sequence of layers deposited in a water body within 1 year. Therefore, varved sequences have been the object of a lot of attention from the paleoscience community because they can provide the highest-resolution paleoenvironmental and paleoclimatic records with accurate chronologies independent of radiocarbon reservoir complications and because they enable one to resolve interannual trends in average and even seasonal climate. Iconic paleoclimatic records, such as the Cariaco Basin or Holzmaar in the German Eifel, are famous varved sequences.

Recently, the PAGES Varves Working Group (VWG) was established within the frame of Cross-Cutting Theme 1 (Chronology) and 2 (Proxy development, calibration, validation) to provide a further impetus for the study of varved sediments. The VWG has the objectives of reviewing what has been accomplished during the last 10 years in terms of new methodological developments and improvements in calibration of records, as well as making an inventory of varved records. Other VWG topics are detailed at http://www.pages.unibe. ch/science/varves/index.html

A group of 41 scientists from 11 countries (including 8 students and 4 young scientists) met for the first VWG workshop in the Palmse Manor House, in Lahemaa National Park Centre, Estonia. The workshop was divided into four oral and one poster sessions (for abstract volume see http:// www.pages.unibe.ch/science/varves/ publications.html). The first session was devoted to the study of the processes responsible for the formation (and preservation) of varves from various environments

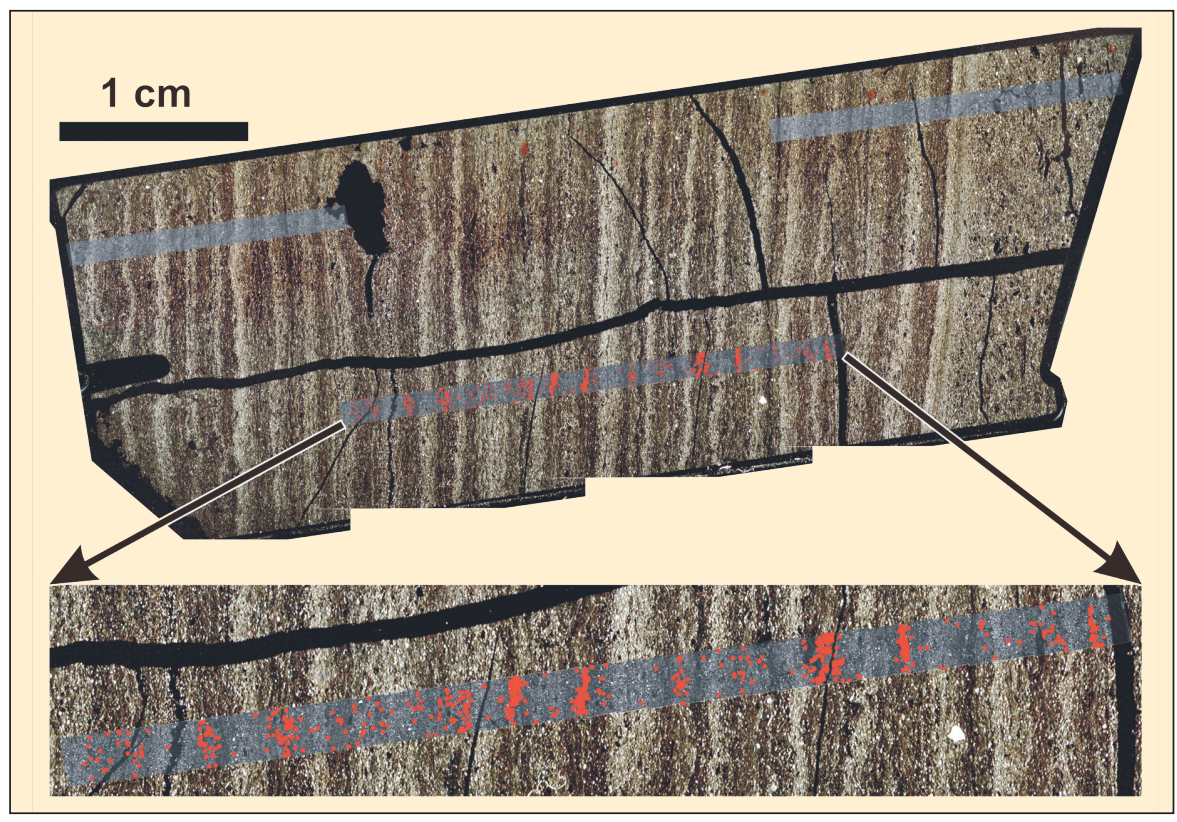

Figure 1: Microscopic view of varved sediments from Lower Mystic Lake, Massachusetts, USA in thin-section (crossedpolarized light). Superimposed grey bands are mosaics of scanning electron microscope images acquired in backscattered mode and used to identify the individual occurrence of the diatom Cyclotella (red dots), which indicates spring blooms and hence confirms the annual character of these laminations. Figure from M.R. Besonen.

in the Canadian Arctic, Western Europe and the Middle East. The second session reviewed advances in the improvement of chronologies of varved records using independent dating techniques, such as paleomagnetic secular variation, tephra horizons and radiocarbon dating, as well as the detailed analysis of internal structures of varves (Fig. 2). The third session was devoted to technological advances in the study of varved and other laminated sediments. It focused on the increasing application of micro-XRF techniques and the development of new softwares helping scientists in the analysis of the large datasets obtained by varve counting. Environmental and climate history case studies from lacustrine and marine sites were discussed during the fourth session. During the poster session, covering all the topics mentioned above, authors briefly introduced their papers to the group.

The workshop participants discussed several practical topics during 3 plenary sessions. They first identified the needs of the VWG community, which included the need for advertising methodological and technical services that can be provided from within the community (e.g., making of thin-section), establishing standards for best practice, promoting systematic comparison of methods, and organization of specialized training courses (e.g., spectral analysis, Bayesian chronological correc- 
tion, image analysis). It was also suggested to implement a website (to be hosted on the PAGES website) with a metadatabase of existing varved records and a database of images of varves.

Key topics to be addressed at future workshops were also discussed. The next workshop will focus on bridging the gap with other communities that deal with the study of archives of past climate with annual resolution, i.e., ice cores, tree rings, corals, and speleothems. Additionally, models and data assimilation communities will be included. This workshop will be held in the USA (exact place and time to be announced). A third and potentially fourth workshop will focus on establishing standards of best practice for the study of varved sediments, and on specific thematic themes such as events, climate variability, calibration and intersite comparisons.
Anybody interested in varves studies and the VWG can register and contribute to activities by contacting the first author.

\section{Acknowledgements}

The organizers wish to thank PAGES, the Geological Survey of Finland, Estonian Environmental Board Visitors Centre of Lahemaa National Park Centre and Emilia Kosonen for their help and support

\section{The $1^{\text {st }}$ Australasia 2k regional workshop:}

Towards data synthesis

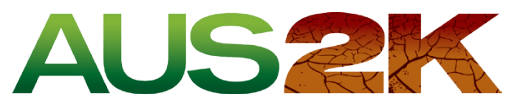

\section{Melbourne, Australia, 31 May-2 June 2010}

\section{Chris Turney' ${ }^{1}$, J. Gergis ${ }^{2}$, A. Lorrey ${ }^{3}$, J. Palmer ${ }^{1}$, S.J. Phipps ${ }^{4}$ and T. van Ommen ${ }^{5}$}

${ }^{1}$ Climate Change and Sustainable Futures, School of Geography, University of Exeter, UK; c.turney@exeter.ac.uk ${ }^{2}$ School of Earth Sciences, University of Melbourne, Australia; ${ }^{3}$ National Institute of Water and Atmospheric Research, Auckland, New Zealand; ${ }^{4}$ Climate Change Research Centre, University of New South Wales, Sydney, Australia; ${ }^{5}$ Australian Antarctic Division and Antarctic Climate and Ecosystems Cooperative Research Centre, Hobart, Australia.

Australasia spans from the tropics to the sub-Antarctic, and straddles several major oceanographic and atmospheric systems that are of global significance and potentially sensitive to anthropogenic-driven climate change. For instance, northern Australasia is influenced by the IndoPacific Warm Pool (Hansen et al., 2006), which is a major source of latent heat and hence drives global atmospheric and oceanic circulation. Towards higher latitudes, the Southern Ocean (south of $45^{\circ} \mathrm{S}$ ) plays a key role in global climate (Caldeira and Duffy, 2000). Although considerable progress has been made in developing quantitative reconstructions of temperature change for the Northern Hemisphere over the past two millennia (Mann et al., 2009), significantly more work is required in Australasia (and the Southern Hemisphere as a whole) (Nicholls et al., 2006).

The first Australasia 2k (Aus2k) regional network workshop aimed to fill this critical gap in climate science by reviewing annually- to centennially-resolved climate reconstructions for Australasia for the past $2 \mathrm{ka}$, towards synthesis in the planned PAGES Regional 2k Network synthesis book. 73 scientists from around the world, representing the proxy, modeling and dynamics communities, met to present the latest datasets and interpretations from across the region.

The first day focused on short presentations and posters of single proxies from the full range of natural archives spanning ice, marine and terrestrial records of the past $2 \mathrm{ka}$. Not surprisingly, tree rings underpin the terrestrial annual resolution record for Australasia (Antarctic ice is great for teleconnections (Fig. 1) but not

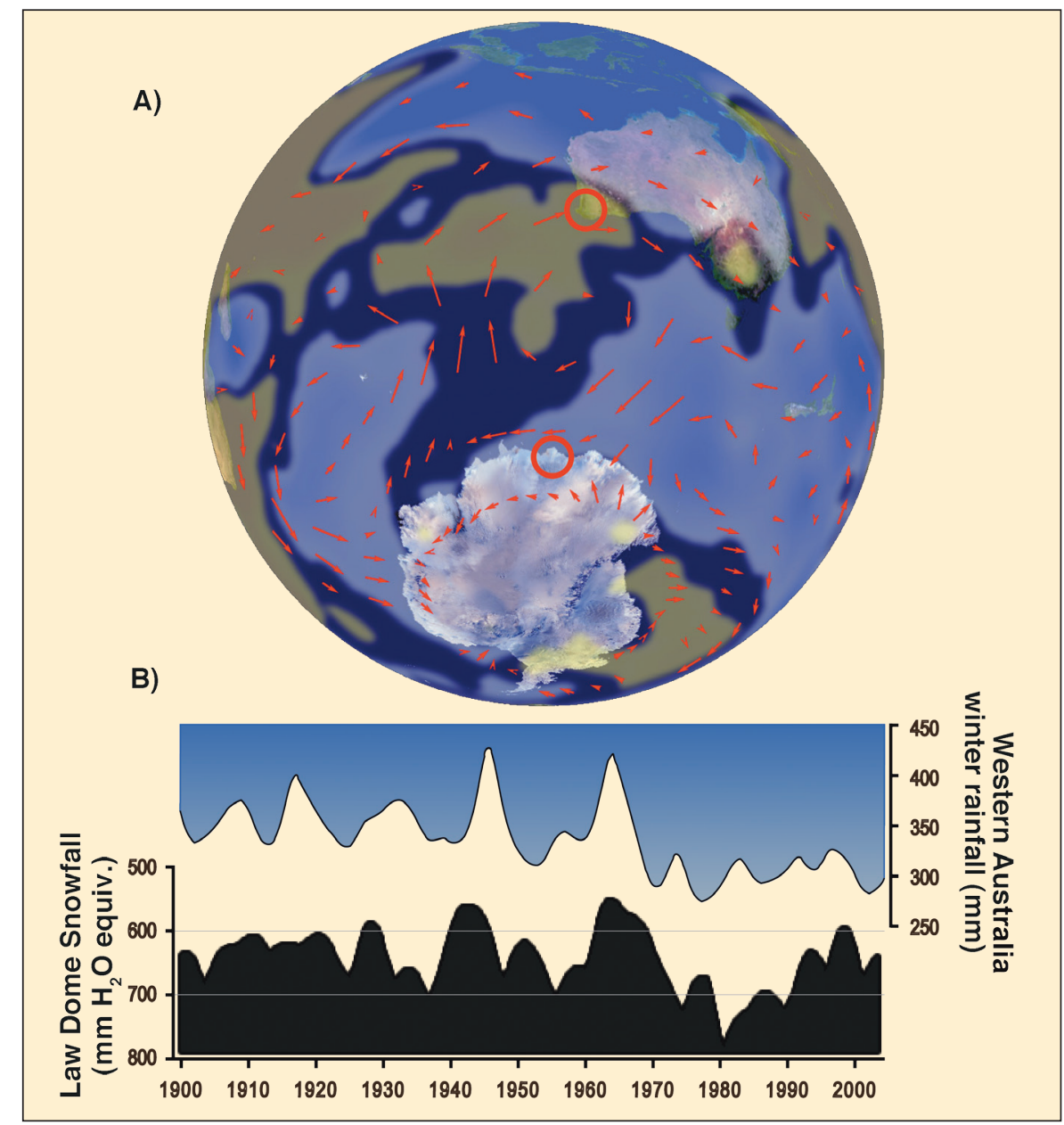

Figure 1: A) Atmospheric water vapor and wind anomalies for years with high precipitation at Law Dome. Blue regions show wet anomalies; tan regions show dry anomalies, which can be seen to extend across southwest Western Australia (SWWA) (Data from NCEP/NCAR reanalysis) (Credit: Tas van Ommen). B) Comparison of SWWA winter rainfall (blue) and Law Dome snowfall (black) since the beginning of reliable rainfall data for WA. The two regions are connected via large-scale meridional flow (van Ommen and Morgan, 2010). The positive precipitation anomaly at Law Dome over the past four decades, corresponding to extended drought in SWWA, is the largest such anomaly in 750 years of snowfall data (Credit: Tas van Ommen/Mat Oakes, Australian Antarctic Division).

local variability). However, the majority of well-replicated records are less than 500 years and only Tasmania and NZ have records extending for the full 2 ka (i.e., a classic "fading record problem"). A surprise was the number of "new" species used in tree-ring reconstructions being developed from throughout the region-vital for understanding geographic variability. A good example is the Western Australian 